
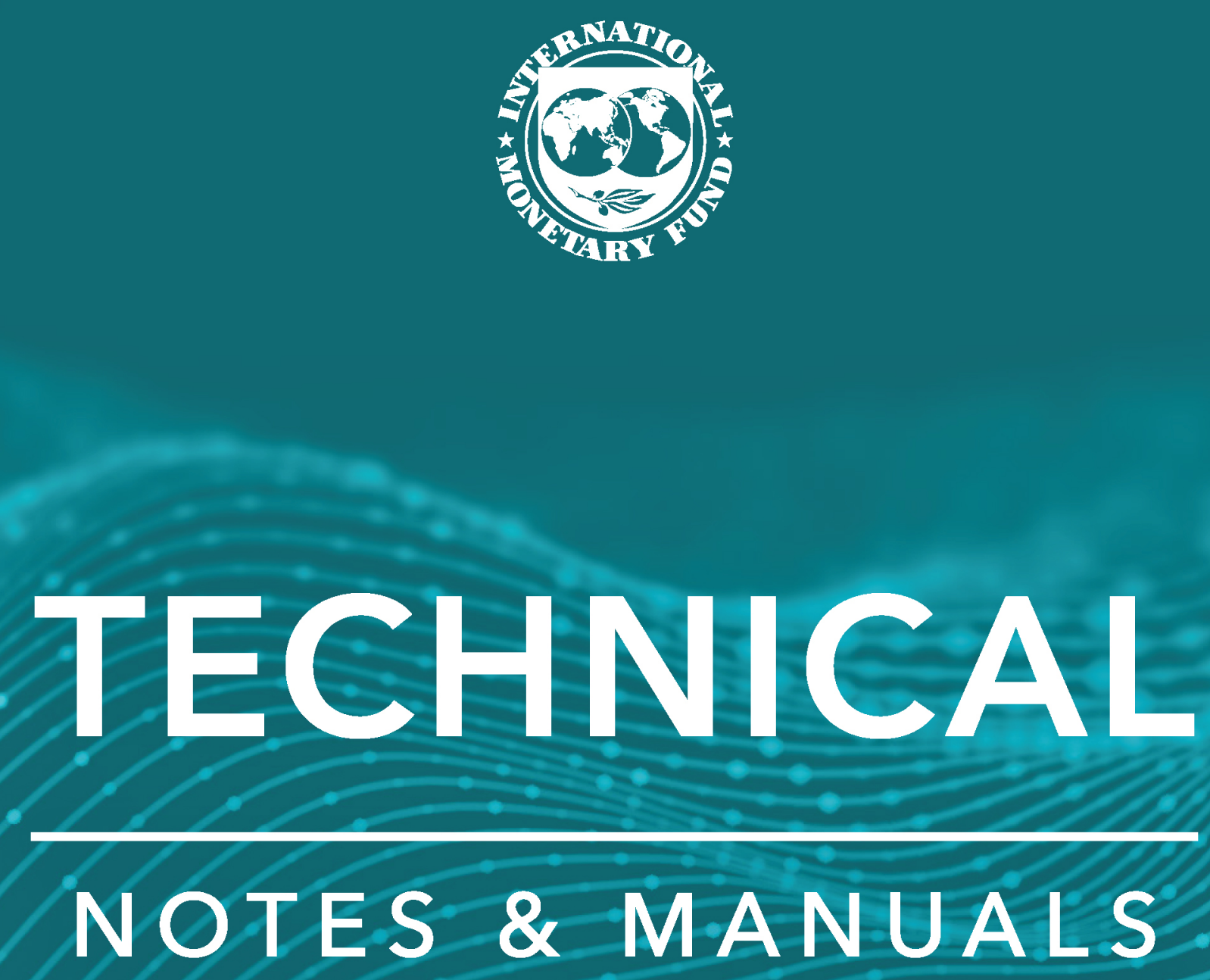

\title{
Integrating the Collection of Social Insurance Contributions and Personal Income Taxes
}

Tony Orhnial 


\section{TECHNICAL NOTES AND MANUALS}

\section{Integrating the Collection of Social}

Insurance Contributions and Personal

\section{Income Taxes}

Prepared by Tony Orhnial

\section{This technical note addresses the following questions:}

- What are the main ways in which different countries assess and collect personal income tax (PIT) and social insurance contributions (SIC) liabilities (Section I)?

- What is the case for transferring responsibility for a country's SIC collection from its social insurance agency(ies) to its tax authority (Section II)?

- What changes does such integration of collection functions involve (Section III)?

- Are there any lessons from international experience to guide such reforms (Section IV)?

- How to build on these lessons when planning a transfer of collection functions (Section V)?

- Are there any beneficial alternatives to full integration of functions (Section VI)? 
Copyright @2021 International Monetary Fund

Fiscal Affairs Department

Integrating the Collection of Social Insurance Contributions and Personal Income Taxes

Prepared by Tony Orhnial ${ }^{1}$

Authorized for distribution by Michael Keen ${ }^{2}$

DISCLAIMER: This Technical Guidance Note should not be reported as representing the views of the IMF. The views expressed in this paper are those of the authors and do not necessarily represent the views of the IMF, its Executive Board, or IMF management.

JEL Classification Numbers: H2, H24, H26, H27, H83

Keywords: Tax administration, Personal Income Tax, Social Security

Author's E-Mail Address: tony.orhnial@yahoo.co.uk

Publication orders may be placed online, by fax, or through the mail:

International Monetary Fund, Publication Services

P.O. Box 92780, Washington, DC 20090, U.S.A.

Tel. (202) 623-7430 Fax: (202) 623-7201

E-mail: publications@imf.org

www.imfbookstore.org

www.elibrary.imf.org

1 Tony Orhnial is a member of the Fiscal Affairs Department's roster of fiscal experts.

2 This note has benefitted from information and comments kindly provided by Debra Adams, Katherine Baer, Patrick De Mets, Liz Gavin, Michael Keen, Aksel Sorensen, and Rebecca Sparkman (all IMF), and Oleksiy Sluchynskyy (World Bank). I am particularly grateful to John Brondolo (IMF) for his generous guidance and advice at every stage in its development. 


\section{CONTENTS}

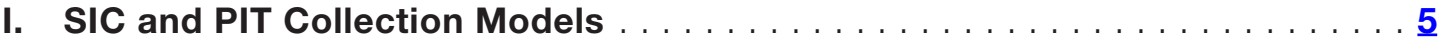

II. The Case for Full Integration of Collection Functions $\ldots \ldots \ldots \ldots \ldots \ldots \underline{7}$

III. The Transition to an Integrated System: What's Involved? . . . . . . . 12

IV. Lessons from International Experience $\ldots \ldots \ldots \ldots \ldots \ldots \ldots \ldots \ldots \ldots$

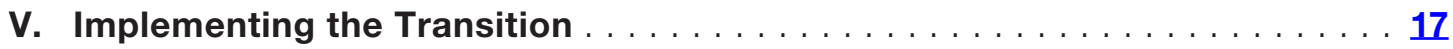

VI. Alternatives to Full Integration $\ldots \ldots \ldots \ldots \ldots \ldots \ldots \ldots \ldots \ldots \ldots \ldots \ldots$

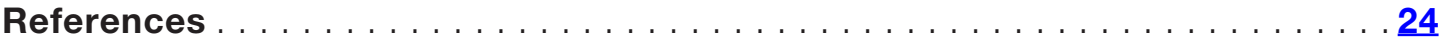

Boxes

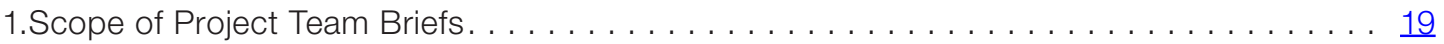

Figures

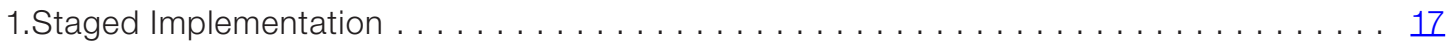

2.The Governance Pyramid . . . . . . . . . . . . . . . . . . . . . . . . . . 18

Tables

1.Exampes of Different Collection Models......................... $\underline{6}$ 


\section{ACRONYMS}

ID . . . . . . . identification

ISORA . . . . . International Survey on Revenue Administration

IT . . . . . . information technology

NICs . . . . . national insurance contributions (the name given to SICs in the UK)

OECD. . . . . . Organisation for Economic Co-operation and Development

PIT . . . . . . . personal income tax

SIA. ....... social insurance agency

SIC. . . . . . social insurance contributions

TA ....... tax administration

UK . . . . . . United Kingdom 


\section{SIC AND PIT COLLECTION MODELS}

It is useful to distinguish between systems in which $\mathrm{SIC}^{1}$ and PIT are collected by separate agencies-parallel collection models_-and those in which both are collected by a single agency-integrated or unified models. ${ }^{2}$ In parallel systems, personal taxes are collected by the country's tax administration (TA) whereas SIC is typically collected by its social insurance authority (SIA) ${ }^{3}$ which also assesses, pays out, and audits individual entitlements to the benefits arising from those contributions. By contrast, in integrated systems, the TA generally collects both PIT and SIC and transfers SIC receipts to the SIA which continues to administer benefit entitlements. Employers normally play a central role in both parallel and integrated systems using their payroll systems to assess and deduct individual employee PIT and SIC liabilities and pay them over to the relevant authority along, where relevant, with employer SIC liabilities.

Historically, most countries' personal tax and social insurance systems were established and developed separately with SIC collection responsibilities initially assigned to their SIA. This has often meant that the rules for assessing liability to SIC have differed from those for PIT and that the collection and other administrative practices of the TA and the SIA have diverged. ${ }^{4}$

Many of these differences stem from the respective purposes of social insurance schemes and general taxation as well as from their underlying design principles. PIT schemes tend generally to reflect the principles of progressive taxation, whereas most SIC schemes were based, at least at their inception, on insurance principles. The latter have been designed primarily to insure contributors against life events and risks relating to their employment and self-employment income by replacing (at least partially) any lost income, with pensions and unemployment, sickness, and disability benefits. In contrast, the purpose of income tax is to generate revenue to fund government expenditure of all kinds. These differences in purpose often manifest themselves in differences in the forms of income subject to PIT and SIC: as discussed later, PIT generally applies to all forms of income without limit whereas SIC tends to apply only to certain forms of employment and self-employment income. ${ }^{5}$

1 In this note, the term social insurance contributions is used to refer to the levy remitted by employees (and often also by their employers) and by the self-employed to gain access to benefit entitlements which are distinct from universal or means-tested social security benefits funded out of general taxation.

2 Barrand and others (2004), pp. 4-12.

3 In order to focus the analysis specifically on the integration of SIC and PIT collection functions, this paper assumes a single SIA. In practice, many countries have, or have had, separate social insurance schemes covering, for example, pensions, medical costs, or unemployment each with its own administrative rules. Where this is the case governments also face decisions about the extent, if any, to which the different schemes should be integrated. Although not covered in this note, much of the analysis set out here could usefully be applied to those decisions. Anusic (2005), pp. 2-9, provides a helpful taxonomy for framing that analysis.

4 Differences in the administrative cultures, histories, and practices of the separate departments tend to be reflected in divergences in their reporting procedures, payment dates, and penalties for non- or late payment; in their powers and methods of investigation, enforcement, and debt pursuit; and in their compliance and customer service strategies.

5 An issue that is not discussed in this note but that continues to attract debate among economists is whether, in order to minimize economic distortions, SICs should, like income tax, apply to income arising from capital as well as from labor. See, for example, Mirlees and others (2011). 
TABLE 1. Examples of Different Collection Models

\begin{tabular}{|c|c|c|}
\hline PARALLEL COLLECTION & INTEGRATED COLLECTION & PLANNED TRANSITION \\
\hline Austria & Argentina* $^{*}$ & Azerbaijan \\
\hline Belgium & Brazil $^{*}$ & China \\
\hline Chile & Canada & Indonesia \\
\hline Croatia & Hungary* & Slovak Republic \\
\hline France & Ireland* & Turkey \\
\hline Germany & Kazakhstan* & \\
\hline Greece & Kyrgyz Republic* & \\
\hline India & Romania* & \\
\hline Japan & Russia* & \\
\hline Mexico & Sweden* & \\
\hline Mongolia & United Kingdom* & \\
\hline South Korea & United States & \\
\hline
\end{tabular}

*Transitioned from a parallel collection model.

SIC-funded insurance schemes come in numerous shapes and sizes, but many countries also provide social assistance through (universal and means-tested) social security benefits and various types of negative income tax schemes ${ }^{6}$ all funded from general taxation. Indeed, over time, some governments have leaned increasingly on the latter and eroded the link between contributions and entitlements in their SIC schemes. A case in point is the United Kingdom (UK) where a recent Institute for Fiscal Studies review remarked that, "National Insurance is not a true social insurance scheme; it is just another tax on earnings," and, "Certainly, NICs originated as a payment made for specific benefit entitlements. But, in practice, the link between contributions and entitlements is now vanishingly weak."

Most countries continue to operate parallel collection systems although the trend in recent years has been toward greater integration. In some cases, this has meant transferring SIC collection responsibilities from a country's SIA to its TA. As discussed further in Section IV, in other cases, where functions have not been formally integrated, it has often involved closer working between the two departments while maintaining essentially separate collection systems. Although no two countries' collection systems are identical, Table 1 lists some examples of jurisdictions operating (broadly) parallel and integrated SIC/PIT collection systems and of countries that are in the process of transitioning to a single system. Details of the nature and extent of collaboration between TAs and SIAs in a range of Organisation for Economic Co-operation and Development (OECD) and other countries are available in the biennial International Survey on Revenue Administration (ISORA). ${ }^{8}$

6 These range from United States' Earned Income Tax Credits to the United Kingdom's Working Tax Credits and Child Tax Credits which, while not technically negative income tax, involve income transfers paid to claimants by the UK tax authority rather than its social security agency.

7 Mirrlees and others (2011), pp. 126-7. See also Timmins (2017), Hills (2015), and Bradshaw (2019).

8 https://data.rafit.org/?sk=57536808-le0c-476f-bc20-afaac069aae8. 


\section{THE CASE FOR FULL INTEGRATION OF COLLECTION FUNCTIONS}

It is important to emphasize that the contrasting concepts of parallel and integrated systems define opposite ends of a continuum with few, if any, practical examples of pure versions of either. Different countries' arrangements generally lie somewhere along that spectrum depending on the degree to which their PIT and SIC assessment and collection arrangements have been brought closer together through policy harmonization and interdepartmental collaboration in collection activities. Nonetheless, where collection functions remain assigned to different departments such closer working between them can often be limited by taxpayer confidentiality restrictions and organizational and cultural boundaries.

The activities of assessing and collecting PIT and SIC share a number of fundamental similarities in that they both require:

- individuals to register and be assigned an appropriate identification number, used to record their payments and any SIC benefits they may be entitled to;

- an assessment of individual PIT and SIC liabilities based on some measure of individual income;

- employers to calculate and deduct those liabilities by means of their payroll system at the same time as any wages due, and to report, and pay over, those deductions to the appropriate authority;

- self-employed and other non-employees to pay their tax and SIC liabilities directly to the relevant collection authority; and

- institutional arrangements to check and enforce compliance by employees, the self-employed, and other individuals, and by employers and other withholding agents and to provide a mechanism for those stakeholders to appeal against administrative errors and malpractices.

Those similarities would suggest that, in principle, administration costs borne by individuals, business, and government could be minimized by adopting:

- a single registration process assigning a unique identifier to each individual linked to a single database $^{9}$ (for both PIT and SIC administration purposes);

- the same set of assessment rules and definitions (applied to the same employment and selfemployment income base) for assessing both levies;

- a unified collection process for PIT and SIC with a single return, identical filing and payment dates, and the same compliance, enforcement, and appeals arrangements; and

- a single agency responsible for collecting both PIT and SIC and for transferring collection proceeds to PIT and SIC accounts respectively.

9 Strictly speaking, a single database is not required as long as the identifier enables the accurate linking of all records held on different databases in respect of a particular individual. 
The case for (or against ${ }^{10}$ ) integrating collection services rests on the opportunities it offers for reducing administration and compliance costs borne by:

- private and public sector employers; and

- individual contributors, including employees and the self-employed;

and for enhancing government revenues by improving taxpayer/contributor compliance and by greater policy harmonization. These potential benefits are discussed in turn, but the scope for such cost savings and revenue enhancements in a particular country depends on the extent of any specific policy and administrative discrepancies at the outset. The degree to which such reform benefits are available in practice varies widely across different jurisdictions sometimes because of political, institutional, or cultural obstacles to closer working between tax and social insurance agencies.

\section{Employer Compliance Costs}

Employers carry much of the cost of administering SIC and PIT collection in both parallel and integrated systems. Payroll-related obligations tend to be the major source of compliance costs for employers in many countries, and particularly for smaller employers. In the UK, these were estimated to amount to $£ 1.3$ billion in 1995-96 in a study ${ }^{11}$ carried out on behalf of the UK tax authority shortly before it took full responsibility for collecting NICs.

Much of the additional administrative cost associated with parallel collection systems stems from the duplication of functions between government departments. These duplication costs can arise from the separate administrative regulations and processes that employers must adhere to in collecting PIT for a country's TA and SIC for its SIA and paying over the receipts separately to the two departments. These additional burdens can include separate employee registration arrangements and identification numbers for PIT and SIC, separate, nonidentical, and uncoordinated collection, reporting, and record-keeping requirements, and different reporting and payment dates. They can also entail the prospect of separate compliance actions, including uncoordinated visits and investigations from the two departments.

The additional private sector compliance costs associated with duplication of registration and collection processes are mirrored in the public sector. The additional costs that arise for private sector employers are also borne by government agencies and state-owned enterprises. And government as a whole also bears the costs of operating two, rather than one, processes for SIC and PIT registration and collection, as well as maintaining separate databases.

\section{Individuals' Compliance Costs}

Employees, the self-employed, and other contributors can also face higher than necessary compliance costs. They often need to undergo different registration processes for tax and for one or more social insurance schemes and also to keep track of their different tax and contribution records. This complexity inevitably introduces unnecessary costs by making it more difficult for taxpayers and contributors to understand and to comply with their PIT and SIC obligations.

10 Section VI discusses the case against full integration and presents some alternative approaches.

11 Collard and Goodwin (1999), pp. 423-49. 


\section{Government Revenues}

For governments, such complexity also means foregoing opportunities to improve user compliance with both PIT and SIC obligations. International experience suggests that processes that users find easy to understand promote better voluntary compliance especially when encouraged by appropriate taxpayer support measures.

PIT and SIC noncompliance are often closely correlated so that the matching of SIC and PIT data is a vital element in effective risk analysis and mitigation. Different identification numbers and databases for PIT and SIC, and separate enquiry powers, can also prevent the development of effective compliance strategies. And this means that the risk of fraud and error in the assessment of liabilities and benefit entitlements is higher than it should be and so SIC, and to a lesser extent PIT, yields are lower than they could be.

\section{Policy Differences}

The private and public sector costs associated with process duplication are augmented by costs that arise from policy discrepancies between the two systems. As mentioned earlier, SIC liability tends to be restricted to employment and self-employment income. However, even on this narrow income base, PIT and SIC definitions of the tax bases may differ: most forms of employment income, including those in noncash forms, are usually subject to PIT whereas income bases for SIC purposes frequently exclude some forms of income, such as certain benefits-in-kind. PIT liability is usually assessed without an upper limit to the income subject to tax whereas upper income limits often apply to SIC liability assessment. For reasons explained earlier, liabilities to PIT and SIC can also differ according to the timing and periodicity of the income brought into charge: whether income is assessed when it is received (the receipts or cash basis) ${ }^{12}$ or when the right to it arises (the accruals basis) and whether liability is assessed on the basis of income received during the whole tax year or in a specific pay period. ${ }^{13}$

As well as making the discharge of employer payroll obligations more costly, such policy divergences offer substantial opportunities to avoid SICs by manipulating the composition of employee remuneration packages. These generally involve paying employees in noncash forms not (at the time) subject to SICs, thus reducing both employee and employer SIC liabilities. In the UK, for example, SIC avoidance schemes used in the 1990s and early 2000s included payment in gold bars, Turkish rugs, and options of various kinds. Such schemes, and particularly those involving shares and share options, are not restricted to the UK. They generally involve exploiting the rules for valuing, for SIC or PIT purposes, noncash remuneration, especially where the future benefit is uncertain at the time those rights are conferred.

Transferring responsibility for SIC collection to a country's TA would provide opportunities for administrative streamlining and for any policy reforms necessary to align income bases. A single registration process and identifier for SIC and PIT, with a single database holding PIT and SIC

12 In Vietnam, for example, PIT is assessed on a cash basis whereas SIC is assessed on an accruals basis.

13 In the UK, income tax liabilities are based on income received during the tax year whereas NICs are based on income received in a pay period (most frequently the month). A review by the UK government (HM Treasury 2007) estimated the benefits and costs of assessing NICs liabilities on a cumulative annual basis like tax and concluded that "on balance the benefits of administrative alignment do not outweigh the costs." 
payment records for every individual, would enable the TA to introduce unified collection processes and integrated compliance and enforcement strategies for PIT and SIC. Such changes would also help improve the SIA's capacity to administer SIC benefit entitlements.

\section{Quantifying the Benefits of Reform}

Although the benefits of unifying PIT and SIC collection systems are widely recognized in principle, they are hard to quantify accurately. This is for a number of reasons:

- business compliance costs, the source of many of the main benefits of such reforms, are notoriously difficult to estimate, not least because of differences in the measurement methodologies adopted by different countries;

- this type of reform is often carried out at the same time as others so that it is difficult to identify separately the effects of each change ${ }^{14}$ and this can be exacerbated by very long lead times;

- the impact of integration measures can be blurred by technological developments such as the introduction of compliance-cost-reducing payroll software while the reform is being implemented; ${ }^{15}$ and

- all too often, post-implementation reviews of administrative reforms are just not undertaken so actual costs and benefits remain unmeasured. This can be because the reforms have proved politically sensitive, making governments reluctant to publish the comprehensive data sets necessary for academic or other external research to take place. ${ }^{16}$

Nonetheless, the scant qualitative and quantitative evidence that is available does lend support to the analytical conclusion that integrating collection functions can produce significant benefits for government, business and individual stakeholders. ${ }^{17}$ For example, the Republic of North Macedonia, which adopted an integrated collection system in January 2009, reported substantial increases in social fund receipts in the first half of 2009, supplemented by reduced employer costs and improved employer compliance. And the UK tax authority, in its evidence ${ }^{18}$ to the House of Commons Treasury Committee, reported that, as a result of the transfer, the number of employer compliance visits had been reduced to 35,000 PIT/SIC integrated visits per year from the previous annual averages of 90-100,000 SIC-related visits plus 40-50,000 PIT-related visits.

14 For example, in the United Kingdom, at the same time as full responsibility for collection of NICs was transferred to the tax authority in 1999, employers became subject to the additional burdens of paying tax credits and collecting student loan repayments. So the net employer payroll burden was argued to have risen rather than fallen-see House of Commons Treasury Committee (2004). And, in some former Soviet bloc countries, such as Estonia, Hungary, and Romania, the move to a unified collection system coincided with other major social insurance reforms—see Barrand ad others (2004) and Anusic (2005).

15 HM Treasury (2007), chap 3.

16 A particularly disappointing example is the very low questionnaire response rate reported by Anusic (2005) which limited the scope of an ambitious empirical research project intended to quantify the net benefits delivered by various SIC/PIT reforms undertaken in European countries in the preceding quarter century.

17 Barrand and others (2004) and Bakirtzi and others (2011), pp. 98-105.

18 House of Commons Treasury Committee (2004), paragraph 23. 
The qualitative evidence, which consists mainly of case studies, also generally supports that conclusion, with the UK, Norway, Sweden, Finland, and Iceland sometimes cited as particular success stories. ${ }^{19}$ And a 2011 study of the experience of five countries-Estonia, Hungary, Italy, the Netherlands, and the UK-concluded that, overall, "The merged collection system is reported to be more cost-effective and efficient than the decentralized one; as a matter of fact, the countries examined in the present research have reported that they are not considering the possibility of returning to the decentralized collection system. The administrative burden for social security institutions, tax authorities and employers is further reduced and the use of new technologies has greatly facilitated the collection procedure. Moreover, the control and enforcement procedures have contributed to contribution compliance which is very important for the viability of the social security systems in a country." 20

19 Anusic (2005), p. 14, refers particularly to the "compliance and collection effectiveness" of their integrated systems.

20 Bakirtzi and others (2011), p. 102, where a decentralized system should be read as referring to parallel collection of PIT and SIC. 


\section{THE TRANSITION TO AN INTEGRATED SYSTEM: WHAT'S INVOLVED}

Creating a unified system for collecting SIC and PIT generally involves transferring responsibility for SIC collection from a country's SIA to its TA. In essence, the transfer plays to the strengths of tax departments, which are generally responsible for collecting a range of government levies and so have more extensive collection experience and, most often, more robust compliance methodologies and enforcement powers than social insurance authorities. Indeed, there are no examples of social insurance agencies taking responsibility for tax collection.

The benefits of such a transition would generally be maximized by harmonizing both the bases for assessing liabilities and the operational frameworks for collection. ${ }^{21}$ Policy changes would involve decisions about whether base harmonization should follow PIT or SIC principles and about the extent to which the rules governing collection should precisely follow current tax collection rules. These decisions would result in consequential changes to both tax and social insurance legislation ${ }^{22}$ and to administration laws governing the activities of both departments. Changes would also be required to existing operational processes and databases, as well as to software and IT systems used by the two agencies and by employers and other stakeholders.

Such harmonization of income bases would involve very significant policy changes although they would greatly simplify the payroll work of employers. ${ }^{23}$ Full alignment of income bases would generally involve bringing into charge those benefits and payments currently excluded from the SIC charge and applying the same rules as PIT for calculating the cash equivalents of those benefits and of any payments in non-cash forms. And the closer the (usually narrower) SIC base is brought to the PIT base, the greater the potential additional SIC yield that would follow at unchanged contribution rates.

Policy decisions would also be needed about whether the harmonized system should follow PIT conventions in other respects. Where relevant, this would include whether to adopt unified rules about when income arises (cash or accruals) and about periods of assessment (tax year or pay period). Finally, decisions would be required on whether to make all taxable income subject to SIC or to apply a cap or upper income limit to the amount of an individual's SIC liability. Although

21 Some countries have chosen to transfer SIC collection to their TA without fully harmonizing PIT and SIC bases and policies thus capturing some, but not all, the compliance cost and other benefits available to employers and governments.

22 Such changes may require the involvement of other ministries, including finance and other key ministries, depending on the institutional legislative arrangements specific to the country in question. So, for example, in the UK the TA is guaranteed an annual finance bill for the enactment of tax and tax administration measures whereas its SIA has to compete against other demands for legislative space in the parliamentary calendar and the support of other key ministries can be critical.

23 In some countries SIC and PIT definitions of what constitutes employment and self-employment can differ and these would need to be addressed as part of the reform, especially where any differences present avoidance opportunities. 
complete harmonization of SIC and PIT rules may offer the biggest benefits, there is nothing to prevent a country from maintaining or adopting different thresholds, rate schedules, periodicity, or other conventions for SIC in order to retain certain social insurance characteristics. ${ }^{24}$

The administrative benefits of the transfer (for government and other stakeholders) would be greatest if the TA were empowered to collect and administer SIC in broadly the same way as if it were another form of personal income tax. To maximize efficiency, the TA would need the legal authority to introduce:

- a single administrative process for PIT and SIC registration with a unique identifier to serve as the basis for a new database to hold the tax and SIC payment records of every individual covered;

- a new single process, with integrated, preferably electronic, forms for employers to report on their own SIC liabilities and on the PIT and SIC withheld from their employees-with similar integrated income-reporting arrangements for the self-employed and other voluntary contributors;

- the same reporting and payment dates for PIT and SIC purposes;

- new provisions allowing employers and others to transfer any SIC and PIT to the TA in a single payment covering both liabilities and enabling the TA to identify and transfer SIC receipts to an SIA account;

- further provisions to credit employee SIC withholdings to their individual SIC accounts in real time to enable up-to-date benefit assessment by the SIA;

- an integrated SIC/PIT compliance and enforcement strategy, with TA audits and investigations, covering both levies, and more effective use of data-matching and other risk-assessment techniques;

- fully aligned interest provisions and penalties for PIT and SIC late payment, nonpayment, evasion, and fraud;

- exchange of information protocols allowing SIA direct or indirect access to individual SIC records for entitlement calculation and compliance purposes; and

- a single process to cover individual complaints and appeals against TA errors and maladministration.

Enabling the TA to carry out these administrative reforms would entail amending any legislation that establishes the collection and other responsibilities of both authorities. In particular, both sets of administrative regulations would need to be comprehensively reviewed to establish and give effect to the changes needed to the current powers of both departments. This would include new provisions to enable the TA to collect SICs, and to disable existing SIA collection powers and restrict them to the administration of benefit entitlements once the new system is in place.

Changes in registration, reporting, and other procedures would also need to be accompanied by significant re-engineering of government and employer computer systems and/or software. The most immediate changes required would be those necessary to:

- establish a new registry of PIT/SIC payers based on a unique identifier;

- reflect any income base harmonization measures;

24 Such differences are generally not very difficult to accommodate in modern payroll software although the resulting system would be less transparent than a fully harmonized one.

Technical Notes and Manuals 21/01 | 2021

CInternational Monetary Fund. Not for Redistribution 
- amend employer payroll software to accommodate changes to reporting requirements (for example, single rather than multiple forms), reporting, and payment dates and to banking procedures; and,

- re-engineer those TA systems, including any accounting and debt management functions, affected by these changes and by the need for the re-engineered IT system to provide (ideally) an integrated view of each individual's PIT and SIC payments.

The reform would also have implications for staff in SIA and TA and in employer payroll departments. Existing and new staff in the TA would need to understand how the new unified system would work and how it would affect their own work allocations. In particular, compliance staff will need training in the conduct of integrated audits and the data-matching opportunities offered by the new registry. Rebalancing the responsibilities of the TA and SIA will therefore require comprehensive change management and internal communication strategies in both departments. ${ }^{25}$

It could also imply adjustments to their respective staff complements. Employer payroll staff will also require training to understand and operate the new system and, to the extent that it produces tangible reductions in payroll work, staff redeployments or reductions might need to be considered.

Stakeholders would need to be made aware of the changes and what they mean for the management of their individual tax and social insurance affairs. This would primarily involve employers, tax advisers, employees, and the self-employed and so require extensive revision of TA and SIA websites, instruction manuals, and guidance. And it should also involve awareness-raising campaigns directed at specific sectors and industries, interactive "webinars" and other online learning tools, and the establishment of one-stop advice centers covering PIT and SIC obligations.

25 Bakirtzi and others (2011), pp. 96-97. 


\section{LESSONS FROM INTERNATIONAL EXPERIENCE}

In making the transition to either a fully integrated or a more integrated system, individual countries have each followed different routes to their chosen outcome. These routes have depended significantly on the precise starting point for the reform including:

- the extent and effectiveness of any existing collaboration between tax and social security authorities;

- the degree of modernization of their respective computer systems;

- the efficiency of their existing processes; and

- the extent of any regional or federal variations in the practical application of PIT and SIC regulations. ${ }^{26}$

However, in spite of these differences, there are some general conclusions or lessons that might help guide any reform of this magnitude. These various insights are embodied in the advice in Section $\mathrm{V}$ on implementing the transition to a unified collection system.

The first is that successful delivery depends critically on obtaining enduring buy-in from all stakeholders, and especially from senior politicians and officials across government. This is particularly important because the transition to an integrated collection system usually takes some years. Employer and more general taxpayer or contributor support is best fostered by conducting open, early, and continuing consultation on the proposed changes. The same is true for working level engagement in all government departments potentially affected by the proposed changes. Continuing commitment from senior officials and politicians is vital to ensure appropriate resourcing and to overcome resistance to the change. ${ }^{27}$

The second lesson is the need to establish at the outset an effective governance framework with clear accountabilities to plan, implement, and oversee the reform. This should generally provide an appropriate role for all relevant stakeholders and recognize and reflect the importance of project management as well as more traditional policy and technical skills. It should also include a comprehensive system for detailed scoping of the changes needed, for monitoring progress, and for identifying and managing risks.

The third is that the IT, legislative, and organizational changes required in each affected department need to be carefully scoped and sequenced at the outset. In general, the creation of new taxpayer/contributor databases needs to be factored in early as they form one of the foundations on which integrated collection systems are built. Legislative and IT-related changes tend to require the most testing and revision and so suggest an early start and sufficient time for repeated

26 Significant variations sometimes develop, particularly in large countries, between provincial practices both in the local application of national PIT and SIC regulations and in local administration. So, for example in China, which is currently considering moving to a unified collection system, in some provinces SIC and PIT collection are administered completely separately, in others the tax authority in effect collects SIC alongside PIT, with other provinces adopting yet different models. In such situations, a key step in the reform is to ensure that one set of rules applies throughout the country.

27 This is perhaps best illustrated by the case of Greece which, supported by the Ministers for Labour and for Finance, began to reform its complex social insurance system in 2016 with a view to transferring SIC collection responsibilities to its TA. Some 18 months later political support had evaporated, and the reform had stalled. 
iterations. And where organizational changes are involved, especially where staff are transferred from one department to another, time is required to explain the nature of the proposed changes, to undertake training, and to obtain staff buy-in.

The fourth lesson is that a phased approach to the implementation of major reforms is significantly less risky than a big bang approach with all parts of the new system being switched on at once. A phased approach allows time at each implementation stage to test or pilot each component of the reform, and especially IT-dependent elements, before moving to the next stage of the plan. The careful sequencing of work on each component is key: priority should be given to foundation elements like databases and to free-standing activities, like arrears collection, that can be used as testbeds without jeopardizing day-to-day business. This enables lessons to be learnt and applied and risks to be mitigated more effectively as the project is rolled out.

Finally, however comprehensive the implementation plan, it should be flexible enough to accommodate any unexpected changes to legislation arising during the IT development and process redesign stages of the project. 


\section{IMPLEMENTING THE TRANSITION}

Reform projects on this scale have the potential to cause major disruption to the day-to-day activities of all stakeholders who depend on the smooth running of the system. These risks, to both the existing and the new system, are best managed and mitigated by staging the implementation of the reform. This involves comprehensive requirement mapping of each component of the reform; repeated testing and refinement until each component achieves an agreed performance standard while the existing system continues to operate until every component is proved to be ready to be brought into play.

The implementation cycle characterizing such an approach may usefully be divided into six key stages. The first two stages lay the foundations for the reform. The next two are about designing, testing, and sequencing each separate component of the reform. The fifth stage entails full implementation of the new system and occurs only when all the individual components are performing satisfactorily. And the final stage, which is about learning how to refine and improve the new system, occurs once it has bedded in. This staged approach is summarized in Figure 1.

\section{FIGURE 1. Staged Implementation}

\begin{tabular}{|c|c|c|c|c|c|}
\hline Stage 0: & Stage 1: & Stage 2: & Stage 3: & Stage 4: & Stage 5: \\
\hline $\begin{array}{c}\text { Set up } \\
\text { governance } \\
\text { structure and } \\
\text { agree plans, } \\
\text { initiate } \\
\text { consultations. }\end{array}$ & $\begin{array}{l}\text { Establish IT } \\
\text { and } \\
\text { legislation } \\
\text { changes } \\
\text { needed for } \\
\text { new } \\
\text { business } \\
\text { processes. }\end{array}$ & $\begin{array}{c}\text { Adopt } \\
\text { legislation, } \\
\text { develop and } \\
\text { test IT } \\
\text { changes and } \\
\text { internal and } \\
\text { external } \\
\text { interfaces. }\end{array}$ & $\begin{array}{l}\text { Pilot, refine, } \\
\text { and finalize } \\
\text { individual } \\
\text { components } \\
\text { of reform in } \\
\text { sequence to } \\
\text { manage } \\
\text { risks and } \\
\text { provide } \\
\text { testbeds. }\end{array}$ & $\begin{array}{l}\text { Final testing } \\
\text { of all } \\
\text { components } \\
\text { and full } \\
\text { rollout of } \\
\text { new } \\
\text { integrated } \\
\text { collection } \\
\text { system. }\end{array}$ & $\begin{array}{c}\text { Overall } \\
\text { project } \\
\text { implementa- } \\
\text { tion review } \\
\text { and future } \\
\text { improvement } \\
\text { plan. }\end{array}$ \\
\hline
\end{tabular}

\section{Stage 0}

Stage 0 lays the first foundations for the reform by establishing a transparent and accountable governance framework and effective internal and external communications strategies. This framework should consist of three basic layers, represented in Figure 2, with a steering group providing strategic oversight and cross-government support for the project; a project management board responsible for overall management and coordination; and specialist project teams providing the detailed planning and implementation work on each strand of the reform. 
FIGURE 2. The Governance Pyramid

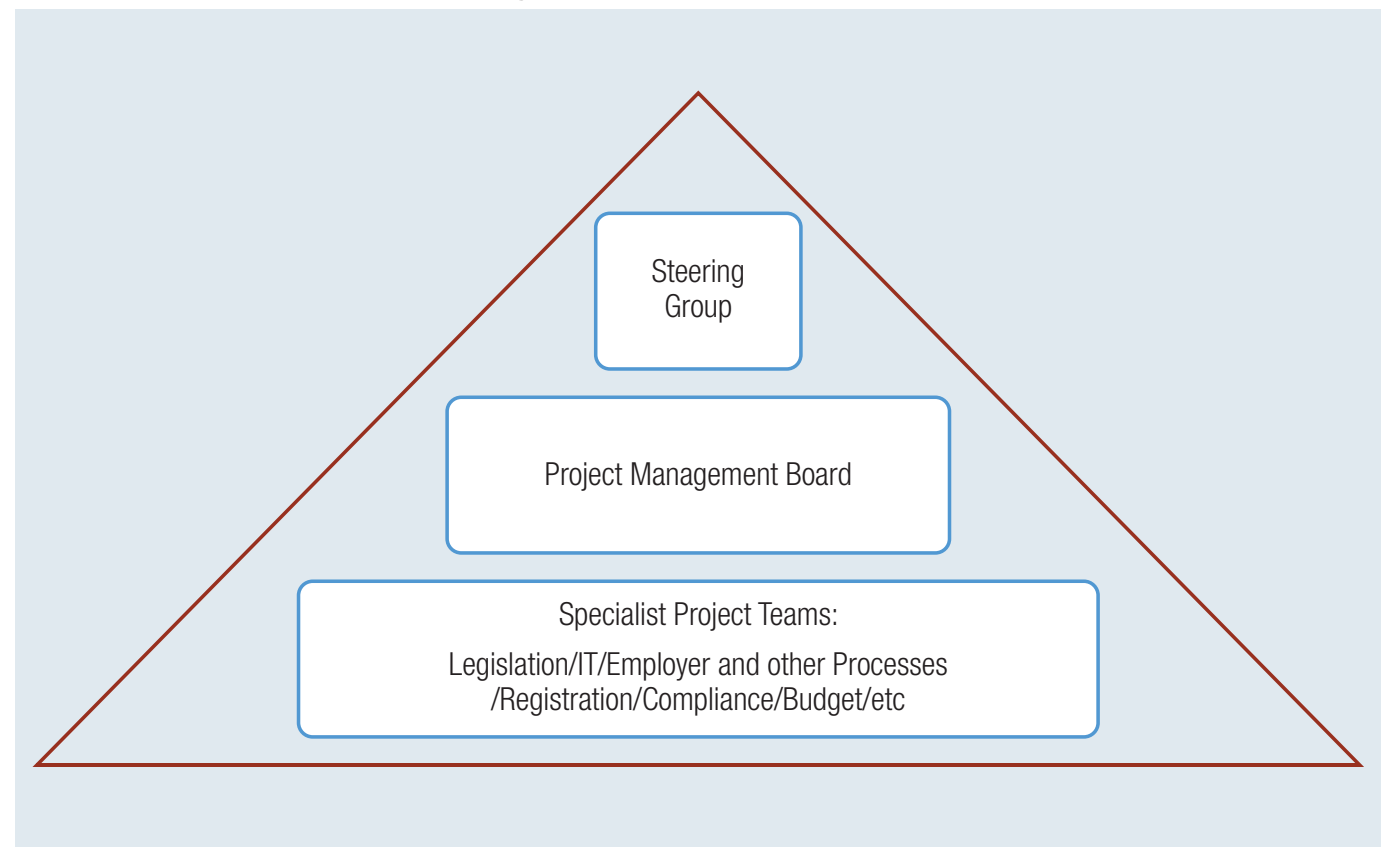

Appropriate staffing—both in terms of skills and stakeholder representation—of each of these layers is important. This should help ensure that the detailed changes necessary are properly scoped and budgeted for, that all stakeholders are consulted, involved, and represented, and that the project receives continuing support at the highest government level.

The steering group should have very senior political chairmanship and be drawn from all ministries with an interest in the reform. In addition to the SIA and TA, the steering group's composition would depend on the specific country's institutional framework. Its job is to provide strategic leadership and direction, to oversee the work of the project board, to resolve interdepartmental disagreements, and to ensure enduring high-level political commitment to the change. Such commitment will usually depend on wider stakeholder support for the project, including one or more nongovernment representatives_-from, for example, bodies representing employers and tax professionals_on the steering group can help secure and maintain that support, as well as providing an external perspective.

The project management board should include experts with relevant technical and project management skills and experience and be chaired jointly by senior TA and SIA officials. It is charged with managing and coordinating the work of the project teams, producing a consolidated budget and timeline and reconciling it with the steering group, and identifying and managing resource bottlenecks and other risks.

Project teams should be staffed full-time by subject experts in the various strands of the reformIT, legislation, operational processes, compliance and investigation, and so on-and should include representatives from both TA and SIA. Their job will be to scope in detail the nature of the changes necessary in their respective areas, to produce realistic timetables and budgets, and to implement those changes in due course. 


\section{Stage 1}

During stage 1 the project teams carry out detailed scoping of the various changes needed in their areas of responsibility. This would include producing resource budgets and implementation timelines which are then tested and consolidated by the project management board and reconciled with the steering group. The work of the project teams needs to cover all the aspects and implications of the reform: legislation, IT, TA and SIA business processes, employer payroll paper and electronic processes, audit and risk assessment routines, banking, accounting, debt management and arrears collection, organizational changes, the transfer, recruitment and training of staff, and employer and other taxpayer information and education. An example of the typical scope of a project team brief is shown in Box 1.

The project management board consolidates the results of these scoping exercises to produce a budget and timeline for the project as a whole. It should also identify potential interdependencies and other risks and develop strategies for managing them, including escalation to steering group level when necessary.

\section{BOX 1. Scope of Project Team Briefs}

Brief for each workstream to include:

- Clear mapping of work to be undertaken

- $\quad$ Timelines for delivery of each work component

- Milestones with delivery dates to allow tracking and early warning of delivery risks

- Dependencies: internal (with other workstreams) and external (with other department and government reforms)

- Connection between workstream activities and overarching reform

- Appropriate parameters to measure success of team's delivery

- Estimated budget including clearly identified contingency

- Details of key staff resources and where/how obtainable

- Workstream risk register

\section{Stage 2}

Stage 2 is the phase during which the agreed changes in all these areas are put in place. Changes in PIT and SIC laws go through their respective legislative procedures and are enacted. Databases and other IT components are developed and tested until they perform satisfactorily, new employer and TA administrative processes are designed and tested, and so on. To reduce risks and promote buy-in, consultation with users, including employers, taxpayers, tax professionals, software developers, and TA and SIA staff, is essential during both the design and testing processes and a formal framework for this should be established. ${ }^{28}$ During stage 2, policy decisions will also be needed on the extent of any income base harmonization and the consequential legislative amendments will need

28 This consultation framework should ideally be foreshadowed in the Stage 0 external consultation strategy. 
to be adopted and reflected in employer payroll specifications and in TA accounting software. The duration of this phase depends primarily on the scale and nature of the legislative and IT changes required and on the institutional procedures that need to be followed to ensure their adoption.

\section{Stage 3}

Stage 3 builds on the foundations of the preceding stages to test and gradually introduce, in an agreed sequence, the various individual components of the reform package. The sequencing of the transfer of functions from SIA to TA should seek to reduce implementation risks by providing opportunities for testing new components as they are developed without disrupting day-to-day operations in either department.

As mentioned previously, the establishment of a unique identifier and new database should occur early in the implementation cycle. The key informational foundation of the new integrated PIT/ SIC collection system is the unique identifier, produced by a new ID registration process. This is a prerequisite for the construction of the new common database underpinning the design and operation of an effective joint compliance strategy and for accurate SIA benefit entitlement administration. Establishing the new database will involve linking the PIT and SIC records of existing taxpayers and contributors and time will need to be allowed to resolve any discrepancies between existing databases.

Another possible candidate for early transfer to the TA is the collection of existing SIC arrears. This would provide a testbed for proving accounting, debt management, and other new processes with minimum risk to day-to-day SIA operations. It would also help test and confirm the accuracy of the new identifier and database, especially where individuals have both PIT and SIC debts, and the robustness of the legal framework governing data exchange and fund transfers between TA and SIA. It would also provide further opportunities for joint working between the two departments.

Risk mitigation would also argue for transferring self-employed SIC collection functions to the TA before moving on to the transfer of employer-related ones. Self-employed receipts are generally dwarfed by those received through employers so this sequencing would provide an effective and low-risk means of testing integrated assessment, reporting, and payment processes before moving to testing the newly designed payroll-based processes. The latter pilots should involve various sizes and types of employers operating in different industries, including more volatile sectors like construction and hospitality.

A further element of stage 3 implementation is consolidating the internal and external communication strategies introduced at stage 0 . Such consolidation should seek to ensure that emerging perceptions of the shorter-term transitional costs and dislocation do not deflect from the longer-term gains to employers, taxpayers, and to government more generally. Where relevant, it should build on consultation framework established at stage 2 .

\section{Stage 4}

Full implementation of the new system (stage 4), with the transfer of all remaining SIC collection functions, should only occur once each of the individual components has been tested and is performing to an agreed standard. At the same time, as the new system is switched on, all aspects 
of the old SIA registration, recording, and collection systems need to be disabled. It is important to maintain the stakeholder consultation arrangements introduced at stage 2 to monitor the impact of the new requirements and any emerging problems (which should be carefully documented).

During this stage it is sometimes helpful to smooth the introduction of the new system by taking a light touch approach with users who make mistakes in the first few months. An approach adopted in some countries is to suspend temporarily any late-reporting and late-payment penalties, especially for smaller employers.

\section{Stage 5}

Following international good practice, a reform implementation plan should include as its final implementation stage a comprehensive post-implementation review carried out by independent experts. This should be undertaken only once the new system is judged to have bedded in. The purpose of this stage is to identify and implement further improvements suggested by early operational experience, to assess and measure the costs and benefits of the reform in steady state, and to learn any lessons that might usefully be applied to future reforms. 


\section{ALTERNATIVES TO FULL INTEGRATION}

There can be no disguising the fact that full integration of SIC and PIT collection functions would involve radical change to existing institutional arrangements. As mentioned at the beginning of Section IV, the nature and scale of the project would depend on the baseline from which a particular country was starting its reform journey. But, in general, it would take several years to implement fully and involve significant risks and substantial resource commitments. ${ }^{29}$ Therefore, it should come as no surprise that such reforms have the potential to provoke institutional and political resistance as they have done in some countries.

However, there are still significant benefits to be had by adopting a less ambitious approach to reform than full-scale integration of PIT and SIC collection systems. Indeed, many countries have sought to capture some of the benefits of integration by:

- bringing SIC and PIT collection processes closer together, eliminating unnecessary duplication, and harmonizing employer procedures;

- coordinating the activities of their TA and SIA more effectively including through collaborative activities such as joint audits involving officials from both departments;

- facilitating the exchange of information between departments; or

- introducing a degree of income base harmonization while maintaining the distinctive characteristics of social insurance schemes.

A variety of partial reform packages can be designed by cherry-picking several of the elements outlined in Sections II and III to suit the particular circumstances of the country in question. These can reduce transitional costs and risks but, commensurately, they yield only partial benefits for government and other stakeholders. The UK, for example, transferred SIC collection responsibilities to its tax authority in 1999 but retains significant differences between its SIC and PIT bases and assesses SIC liabilities on a pay period basis and PIT liabilities on an annual cumulative basis. But this approach reduces both the potential yield from a wider SIC base and the associated compliance cost savings for employers and others-UK employer organizations continue to lobby for greater harmonization notwithstanding the transitional costs involved.

Not introducing unique identifiers and an integrated database sacrifices record accuracy, easy cross-checking of PIT and SIC income declarations, and other compliance-related benefits. Aligning SIC and PIT processes, payment, and reporting dates; closer working between the TA and SIA; and joint compliance strategies can yield some of the administrative cost savings of single department collection but they cannot completely eliminate duplication. For example, joint TA/ SIA audit visits mean one visit instead of two, but they generally mean a team of two auditors making the visit rather than a single TA auditor carrying out an integrated audit.

A possible hybrid package could include harmonizing income bases and filing and payment dates, strengthening exchange of information between TA and SIA, and coordinating their operational activities more closely. The transitional costs and risks associated with this approach would be significantly lower than for the full integration approach, but so would the benefits expected to

29 HM Treasury (2007), chapter 5, and Adam and Loutzenhiser (2007). 
flow from it for both government and employers. There would still be two sets of identifiers and databases, two departments carrying out essentially the same collection function, and two sets of regulations and processes for employers and others to contend with.

That reform package could be strengthened by adding to it the early introduction of a unique identification number and the construction of an integrated PIT/SIC database. This would clearly entail higher costs and risks but would bring with it the benefits, for employers and taxpayers, of a single registration process and identifier and, for government, of easier cross-checking and more effective investigatory analyses, and of more accurate, comprehensive, and easily accessible records. But again, the potential benefits delivered would fall short of the more radical option.

Another approach would be to dilute the transitional costs of implementing the reform by spreading them over a longer period, giving all stakeholders longer to adapt to the change, while delaying the full benefits of the change. This approach has been adopted in one form or another by a number of countries. For example, the Netherlands started its reform program in 1990 with measures to integrate its various social insurance schemes but only completed the transfer of collection functions to its TA in 2006. In some cases, the ultimate destination has not always been announced at the outset, often because it has not been determined, or has been deferred, or is regarded as too sensitive to make public at that time. Broadly speaking, this describes the UK trajectory where its tax authority started acting as the collection agent for its social insurance department in 1975 but only took on full collection responsibilities in 1999 and did not introduce a single PIT/SIC database until 2009.30

Finally, even if the option chosen falls short of full integration, staged implementation, adapted to reflect its smaller scale, remains the most effective means of managing any risks associated with integration. However, to assist the scoping and planning process carried out by project teams and the project management board, it is also important to be clear at the outset whether the hybrid package is as far as the government plans to proceed or whether it is just the first phase of a reform whose ultimate objective is the transfer of all SIC collection functions to the TA.

30 See Bakirtzi and others (2011), pp. 72-83.

Technical Notes and Manuals 21/01 | 2021 


\section{REFERENCES}

Adam, Stuart, and Glen Loutzenhiser. 2007. Integrating Income Tax and National Insurance: An Interim Report." IFS Working Paper 21/07, Institute for Fiscal Studies, London.

Anusic, Zoran. 2005. "International Experience in Consolidated Social Contributions and Tax Collection, Reporting and Administration." World Bank internal report, Washington, DC.

Bakirtzi, Effrosyni, Paul Schoukens, and Danny Pieters. 2005. "Case Studies in Merging the Administrations of Social Security Contributions and Taxation." European Institute of Social Security, Leuven, Belgium.

Barrand, Peter, Stanford Ross, and Graham Harrison. 2004. "Integrating a Unified Revenue Administration for Tax and Social Contribution Collections: Experiences of Central and Eastern European Countries." IMF Working Paper 04/237, International Monetary Fund, Washington, DC.

Bradshaw, Jonathan. 2019. Let's Talk About Tax: How the Tax System Works and How to Change It. London: Child Poverty Action Group.

Collard, David, and Michael Goodwin. 1999. "Compliance Costs for Employers: UK PAYE and National Insurance, 1995-96." Fiscal Studies 20 (4): 423-49.

Hills, John. 2015. Good Times, Bad Times: The Welfare Myth of Them and Us. Bristol, UK:

Policy Press.

HM Treasury. 2007. Income Tax and National Insurance Alignment: An Evidence-Based Assessment. Norwich, United Kingdom: HMSO.

House of Commons Treasury Committee. 2004. "The Administrative Costs of Tax Compliance, Seventh Report of Session 2003-04." May.

Mirrlees, James, Stuart Adam, Tim Besley, Richard Blundell, Stephen Bond, Robert Chote, Malcolm Gammie, Paul Johnson, Gareth Myles, and James M. Poterba. 2011. Tax by Design: The Mirrlees Review. Oxford: Oxford University Press.

Timmins, Nicholas. 2017. The Five Giants: A Biography of the Welfare State. Third edition. Glasgow, Scotland: William Collins. 